\title{
Strategic use of Manhattan: An Internet communication tool used with a freshmen engineering design course
}

\author{
Steven Schreiner, Thomas Keyser, Ronald Musiak, Richard Mindek, Mary Vollaro \\ Western New England College, Springfield Massachusetts
}

\begin{abstract}
Internet communication tools augment many engineering curricula. We have strategically implemented Manhattan Virtual Classroom, an Internet communication tool developed at our College, for a freshmen introduction to engineering design course taught by five professors. Even though this is a hands-on course that demands face-to-face communication between constituents, we have effectively incorporated this internet-based tool and made it an integral part of the course. This software has benefited our students and professors and is now freely available to colleges and universities that would also benefit from its use with a variety of courses.

Manhattan Virtual Classroom is a versatile tool that allows user-defined levels of communication from simple e-mail to full online courses with little training required for instructors and users. The software has specific modules that enable various types of synchronous and asynchronous communication between professor and student, between students, between student teams, and between instructors. Each instructor is able to easily design the communication interface for their particular section, fitting their own teaching style and allowing greater buy-in and usage by both instructor and students.

The course evaluation included an opinion survey of the students' reaction to the online components and an investigation of server statistics. These data show that Manhattan: aided student learning; increased professor to student communication, facilitated grading and returning of computer-based student work, aided freshmen academic advising, and improved coordination of the course between professors. Somewhat surprisingly, the students did not utilize the peer-topeer communication tools (available to individuals and teams) to the level expected. Overall, we have successfully balanced the integration of on-line communication into a course with handson, problem-based learning that demands face-to-face contact between professor and student.
\end{abstract}




\section{Introduction}

The term "online course" is a broad term that has many meanings. In the strictest sense an online course refers to courses that have no traditional classroom components and the students and instructor never meet face-to-face - this is a true "distance-learning" experience. Without a doubt, an online course provides a 'different' learning experience for most students than a traditional classroom environment.

Undergraduate engineering curricula have been slow to adopt online courses as a mainstream option. Many professors believe that engineering courses require face-to-face communication for several reasons including:

- The presentation of complex concepts underpinning most engineering courses is best delivered in person.

- The hands-on nature of the laboratory exercises cannot be properly mimicked online.

- Real-time feedback from students as to the depth of understanding of the material is needed for effective teaching.

- The spontaneous, peer interaction found in a classroom cannot be duplicated using synchronous web tools.

- Many undergraduate students do not have the maturity and self-discipline required to get the most out of an online course.

Additionally, lack of enthusiasm for online courses among many engineering professors may come from the increased effort associated with preparing and delivering an online course compared to a traditional course offered in a lecture format.

Despite the inertia associated with traditional engineering curricula, there are promising examples of online experiences. Sharma and Fetter from the University of Wyoming have a thorough implementation of an online undergraduate thermodynamics course in which the assessment of student learning is being considered [1]. Moreover, they are attempting to compare traditional delivery with online delivery. At the freshmen level, Carr, et al. from Drexel University have implemented remote web-based experiments, augmenting a traditional introductory laboratory [2]. These two examples illustrate the range of applications that exist.

In freshmen engineering program at Western New England College, we are taking a pragmatic approach to online interaction. Rather than offer online courses as defined above, we offer $\boldsymbol{w e}$ benhanced courses in which we keep the rich interaction of a dynamic classroom environment while significantly increasing communication among instructors and students.

At the University of California at Berkeley, Li, et al. developed a pilot web-based communication tool to support engineering design teams [3]. Baxter at Rensselaer Polytechnic Institute used a commercially available software package to design an online course to teach solid modeling to freshmen [4]. Western New England College's freshmen program involves design teams, solid modeling, as well as other engineering 'tools.' Using Manhattan Virtual Classroom, we have successfully enhanced the teaching of these concepts to first semester freshmen. 


\section{Manhattan Virtual Classroom}

There are several commercially available software packages that address online interaction for education including WebCT and Blackboard. Prior to these packages being widely used, Western New England College began developing its own web-based software to facilitate classroom instruction. This software has been under continuous development for several years and is now available free of charge to other colleges and universities.

Manhattan Virtual Classroom ('Manhattan' from this point forward) is a software package that facilitates distance learning. Faculty can quickly and easily configure modules that will assist in communication among faculty and students over the Internet. By selecting the type of modules, instructors can offer varying degrees of engagement over the Internet: from simply posting announcements to offering a course completely over the Internet.

Figure 1 shows the modules available with Manhattan. Configuration of a Manhattan course is simple and no knowledge of web page construction is needed. Essentially, the instructor decides which modules to turn on and may need to perform minor configuration for that module.

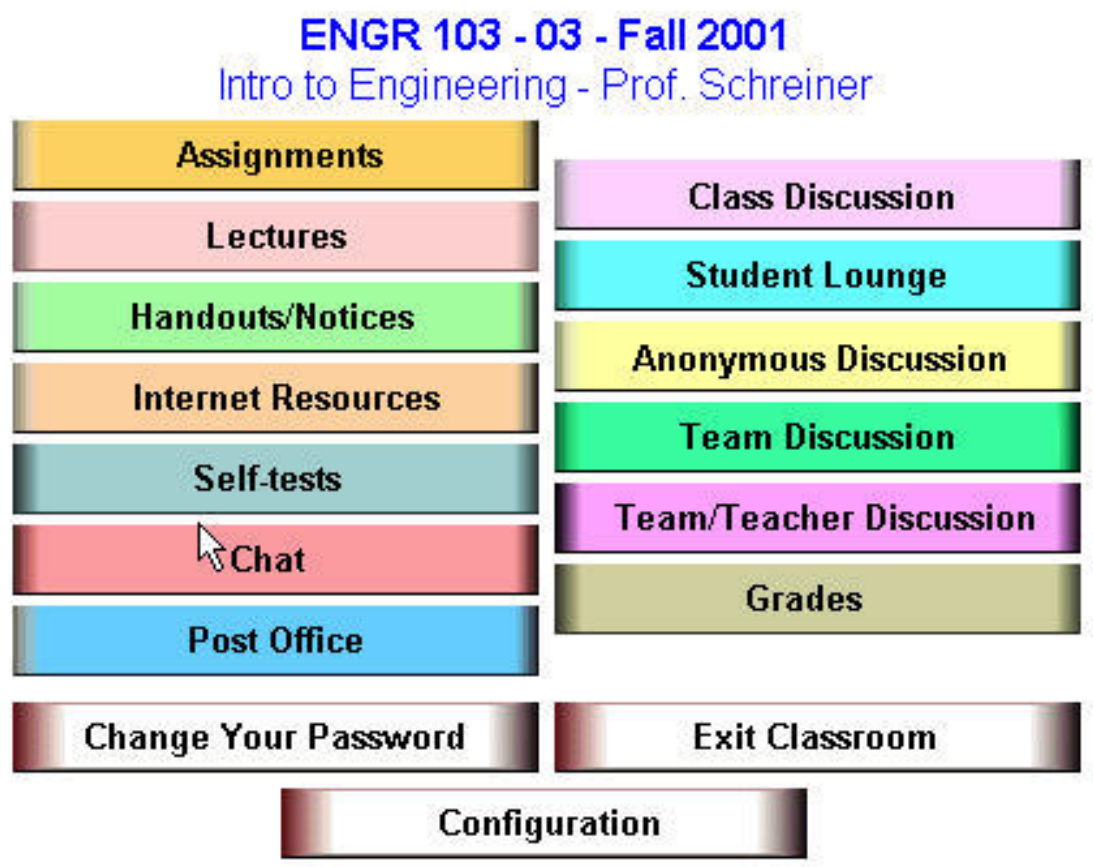

Figure 1 - Manhattan modules available to an instructor

The Chat module allows for synchronous communication, while the other modules offer asynchronous communication. The Self-tests, Lectures, and Handouts/ Notices modules allow for one-way communication from the instructor to the student. Post Office works like traditional email and is a good way for the instructor to organize student email by course instead of overwhelming the instructor's "main" campus email. The Assignment module allows professors to set up individual class assignments. Students respond to these assignments by attaching files or writing messages for each assignment. Since the Assignment module organizes messages by student, the instructor can see at a glance those 
students that have turned in an assignment. The Internet Resources module organizes and tracks student visits to relevant web sites assigned or suggested by the instructor. Class Discussion allows for asynchronous posting of messages for the entire class to read. Similarly, Student Lounge allows for class-wide posting, but can be used for discussions that are perhaps not directly relevant to course content. Anonymous Discussion allows a forum for class participants to share ideas about sensitive topics that they may otherwise be unwilling to share. Team Discussion facilitates team communication - this module allows the instructor to assign students to specific teams. Teams can communicate directly with the instructor with the Team/Teacher Discussion module. The Grades module allows the instructor to upload an Excel Spreadsheet to the server; students may view only their own grades. The Configuration module is only visible and available to the instructor - this module allows the instructor to configure the course modules, track student usage, and manage student enrollment in the course.

Manhattan was developed by Western New England College and is freely available to other Institutions. The Manhattan website, http://manhattan.wnec.edu/, contains more information.

\section{Introduction to Engineering at Western New England College}

The first semester freshmen engineering curriculum at Western New England College incorporates an introduction to engineering design course that requires two major design projects and emphasizes hands-on, problem-based learning; this class represents one fourth of the students' course load. Through a highly coordinated effort, five professors each teach a section of $20-24$ students and serve as the students' academic advisor. In the fall 2001 semester, Manhattan has become invaluable for the execution of the course, even though the instructors meet face-to-face with their class sections for two, three-hour periods each week.

The School of Engineering freshmen curriculum was significantly modified in the fall of 2000 when the content and organization of three freshmen engineering courses were revamped. Introduction to Engineering (ENGR 103), a four-credit course in the first semester, resulted from that effort [5]. Students passing this course were able to:

- Follow an engineering design process

- Reduce \& present data in an engineering manner

- Work on a design team

- Communicate technical information effectively

- Articulate concepts of professional ethics and the social responsibility of engineers

Along the way to achieving these objectives, students learned key computer skills and improved their two-dimensional and three-dimensional visualization skills by studying solid modeling and traditional engineering graphics techniques (by hand).

This course required two major design projects and emphasized hands-on, problem-based learning. In a shift from traditional classroom lectures, instructors delivered short lectures and supervised hands-on activities in two three-hour sessions per week. The design process served as the main theme of the course while the computer tools and other skills acquired during the semester aided student teams in carrying out two significant design projects during the semester. An important organizational caveat was that the instructor of each section also served as the 
academic advisors for the students, greatly increasing the effectiveness of advising these young engineers.

In the fall of 2001, the second instance of this course was delivered by five faculty members, each responsible for one section of 20-24 students. It was clear from the first instance of this course in the fall of 2000 that communication among faculty members and students was critical for keeping the multiple sections synchronized and a means was needed to handle the large volume of submitted material that occurred weekly. It was decided to incorporate Manhattan into ENGR 103 to address these needs.

\section{Faculty Adoption}

Manhattan was made available to each faculty member; adoption and level of use was left up to each faculty member. All five instructors incorporated Manhattan into their sections. A workshop was available to faculty members - some participated, while other choose to learn on their own or had previous experience. Different instructors used the virtual classroom in ways to augment their teaching style. Table 1 shows the modules that the each instructor made available to students.

Table 1 - Manhattan modules selected by each professor. An ' $X$ ' in a column indicates that the professor offered the students in their section the use of the module.

\begin{tabular}{|c|c|c|c|c|c|c|c|c|}
\hline Professor & 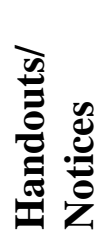 & 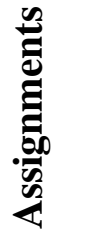 & 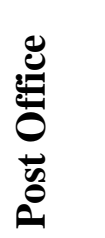 & 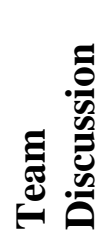 & 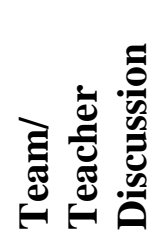 & $\frac{\mathscr{E}}{\tilde{T}}$ & 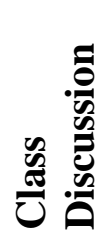 & 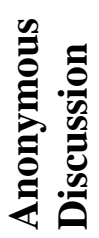 \\
\hline Keyser & $X$ & $X$ & & & & $X$ & $X$ & \\
\hline Mindek & $X$ & $X$ & X & X & X & $X$ & $X$ & $\mathrm{X}$ \\
\hline Musiak & $X$ & $X$ & $X$ & & & & & \\
\hline Schreiner & $X$ & $X$ & $X$ & $X$ & $X$ & & & \\
\hline Vollaro & $X$ & $X$ & $X$ & & $X$ & & $X$ & \\
\hline
\end{tabular}

As the intent was to use Manhattan to enhance the existing course, it was agreed that the software would not be used to reduce the number of classroom contact hours - classroom contact hours remained at six per week.

Using the functionality of Manhattan, the instructors were able to incorporate a variety of functions and accomplish several objectives:

- The instructor easily issued handouts and clarifications at any time through the Handouts/ Notices module.

- Feedback on computer assignments was given directly on Manhattan and did not take up class time.

- Computer-based quizzes were executed in class and turned in directly to Manhattan; time stamping allowed the instructor to be certain that only the allotted time was used. 
- The software allowed the faculty to avoid clogging their campus email service classroom email remained with Manhattan.

- The faculty used Manhattan as a depository for course material and any changes for the next year by creating another 'virtual' section of the course only accessible to faculty members. This depository helped organize the material for the next iteration of the course.

\section{Student Survey}

Students' opinions about Manhattan were surveyed at the end of the semester. The survey indicated that a majority of students thought that Manhattan aided in learning and hoped to see it used in classes in the future. It should be noted that opinion surveys are only indicators of general trends and are difficult to rely upon for fine resolution. A case in point: the students had the impression that they used Manhattan more often than the server statistics revealed.

Eighty-eight students out of ninety-three students sitting for the final exam responded to the survey. The students were asked to rate their degree of agreement with a series of statements. The complete survey results can be found in the Appendix. A scale of one to five was used to rate the degree of agreement with a statement $(5=$ Emphatic agreement, $4=$ Strongly agree, $3=$ Agree, 2 = Weakly Agree, 1 = Do not agree, and N/A = Not applicable or never tried that). Even though this scale is biased towards agreement, we never intended this scale to provide a high resolution; rather we were looking for strong opinions only. For purposes of discussion, responses of 4 and 5 are combined and considered "strongly agree" and indicate the strongest indicators, while a score of 1 or 2 are considered a weak or negative response to the statement.

As expected, most students (85\%) strongly agreed that they were comfortable using computers prior to enrolling in this class (see "statements about background information" in the Appendix). Prior to this class, $91 \%$ of students had never used Manhattan software, but $50 \%$ had used similar communication software in high school or previous college classes (34\% strongly agreed with this statement). The fact that so many have used this kind of Internet medium prior to this freshmen class shows that efforts of high schools to incorporate Internet communication tools into the curriculum are reaching many students. Unfortunately, we do not know the exact type of software used and we plan to survey the students for this detail next year.

The students unitized Manhattan to increase communication with the professor more than with their peers. A majority (53\%) strongly agreed that communication with the professor increased due to Manhattan while 17\% were in weak agreement, disagreed, or had no opinion on the matter (see "statements about communication" in the Appendix). Only 15\% strongly agreed that communication with their peers increased as a result of Manhattan, while $71 \%$ were in weak agreement, disagreed, or had no opinion on the matter. A similar lack of communication benefit between teammates was observed. The peer and team communications is clearly affected by the modules available to the different sections, specifically the post office and discussion modules. Each section offered some form of peer communication (Table 1), but responses from the individual sections did not vary from the overall result - less than $25 \%$ of the students in each section strongly agreed with the statement that Manhattan increased peer or team communication. Even those sections that explicitly offered team modules observed very little if any communication under those modules. 
For many, Manhattan increased their learning experience (see "statements about learning in the Appendix"). Thirty four percent agreed and 30\% strongly agreed that Manhattan played a positive role learning the course material. Thirty five percent agreed and 30\% strongly agreed that the course would have been more difficult without Manhattan. Only a handful (7\%) thought that Manhattan made the course material more difficult. These students may be referring to technical problems associated with a particular network in one laboratory this past fall. Difficulty logging on to Manhattan and frequent computer system failures were occurring, particularly late in the semester when this survey was administered.

Students felt that they used the Assignment Module most (see "statements about module usage in the Appendix). Four of the five instructors required the use of this module to hand in computer assignments for grading; one instructor left it as an option with some students preferring the tactile feedback of handing a Zip disk to their instructor. Many students have the impression that they used Manhattan more often than they actually did. Figure 2 shows a histogram of student logins derived from the actual server data. If a student logged in at least once a day for a 14week semester, they would record 98 logins, assuming a 7-day week. The survey allowed for multiple choices on this question; variable phrasing was allowed. In those 10 cases where students picked two login rates, the lower rate was included in the opinion and is shown in Figure 2. A possible explanation for the students' impression is that the students may have been biased by the login activity at the time of the survey; these data may not reflect a consistent behavior for the semester.

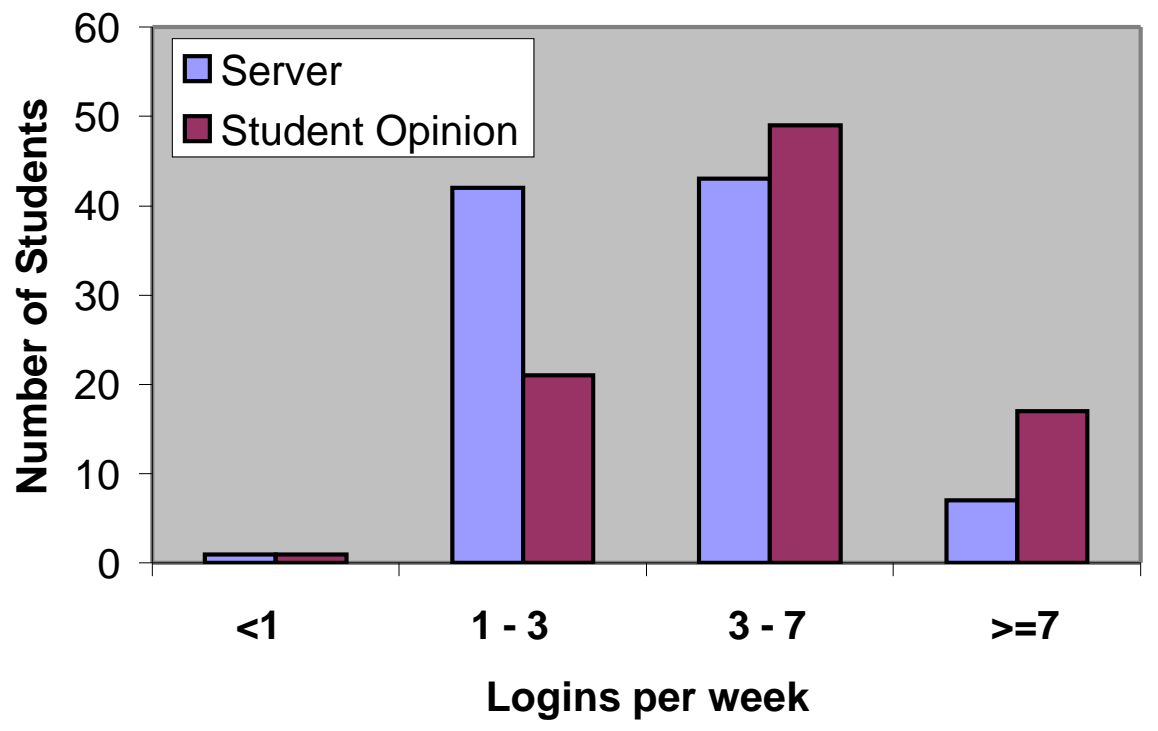

Figure 2 - Actual login data from server compared to student opinion on login frequency. Notice that students are under the impression that they logged in more often than they actually did. Assuming a 14 week semester, the average weekly login rate corresponds to the total number of logins as follows: an average weekly rate of less than 1 corresponds to a student logging into Manhattan fewer than 14

times during the semester; 1-3 logins per week $=14-41$ logins during the semester: 3-7 logins per week $=42-97$ logins during the semester; $>=7$ logins per week corresponds to 98 or more logins during the semester. 


\section{Conclusions}

Manhattan Virtual Classroom was used to create a web-enhanced introduction to engineering course. The data show that the students used the web to increase communication with the professor. Somewhat surprisingly, the students in those sections that offered team communication tools only used them sparingly. This is counter to the complaint that students have difficulty meeting team members outside of class time; perhaps students have less trouble than they admit meeting with each other beyond the classroom. Most students utilized the software well and averaged about 3.5 logins per week. Professors used Manhattan for handing in assignments, returning graded assignments, giving computer-based quizzes, improving the freshmen advising function, dissemination of handouts, clarification of information between classes, and coordination and documentation of the course among the five sections. Overall, students and professors feel that Manhattan aided their achieving the objectives of the course. We have truly enhanced traditional classroom interaction with the use of Manhattan.

\section{Acknowledgements}

The authors wish to acknowledge the aid of Ms. Ann Giguere in compiling the student survey statistics and the Davis Educational Foundation for supporting faculty workshops on the use of Manhattan.

\section{References}

[1] Sharma,M.P., Gary P. Fetter. "Designing, Developing, and Implementing an Online Engineering Thermodynamics Course Using Web Technology." Proceedings of the ASEE Annual Conference, Albuquerque, NM. June 24- 27, 2001.

[2] Carr, Robin, Andrew Gregorowicz, Adam O'Donnell, Robert Quinn. "Enhancement of freshman engineering laboratory through remote web-based experiments." Proceedings of the ASEE Annual Conference, Washington, DC. June 28-July1, 1998.

[3] Li, Francis, James A. Landay, Anthony D, Joseph. "Supporting Collaborative Teams in Engineering Education." Proceedings of the ASEE Annual Conference, Albuquerque, NM. June 24- 27, 2001.

[4] Baxter, Douglas H. "Examining the Benefits of a Self-Taught Solid Modeling Course." Proceedings of the ASEE Annual Conference, Albuquerque, NM. June 24- 27, 2001.

[5] Ronald E. Musiak, Eric W. Haffner, Steven Schreiner, Alan K. Karplus, Mary B. Vollaro, and Richard A. Grabiec. "Forging New Links: Integrating the Freshman Engineering Curriculum." Proceedings of the ASEE Annual Conference, Albuquerque, NM. June 2427, 2001. 


\section{Appendix - Student Opinion Survey Results}

Students were asked to rate their level of agreement with each statement on the following scale: ( 5 = Emphatic agreement, $4=$ Strongly agree, $3=$ Agree, $2=$ Weakly Agree, $1=$ Do not agree, and N/A = Not applicable or never tried that).

\section{Statements on background information}
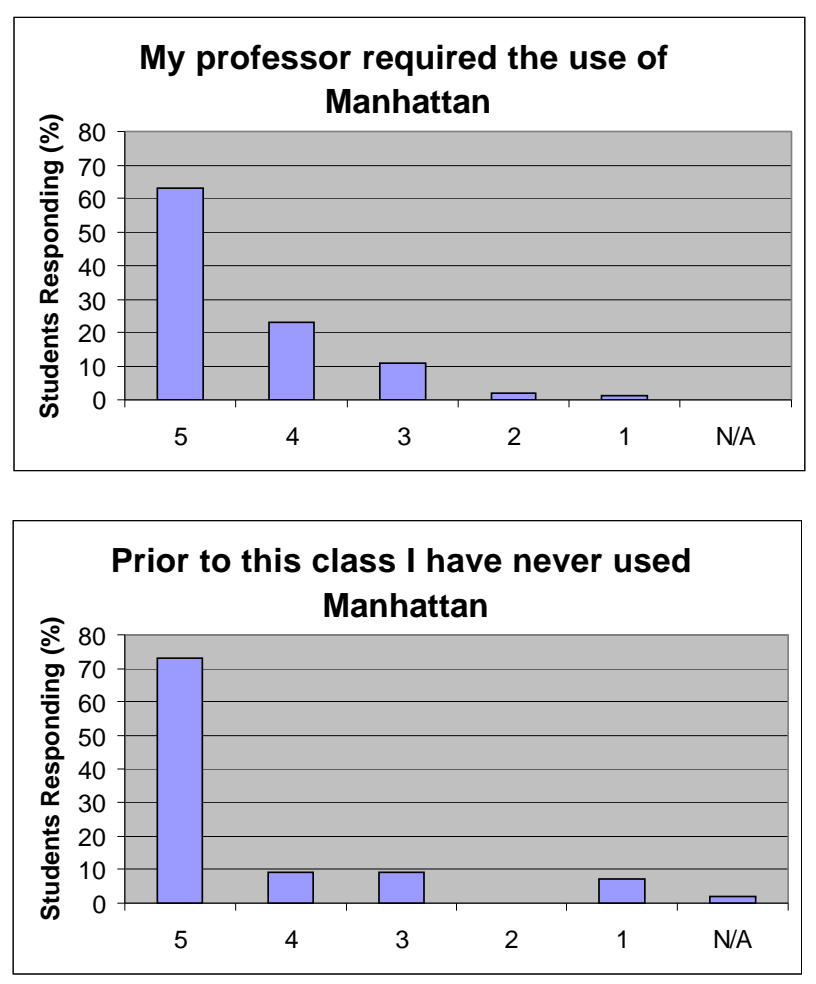
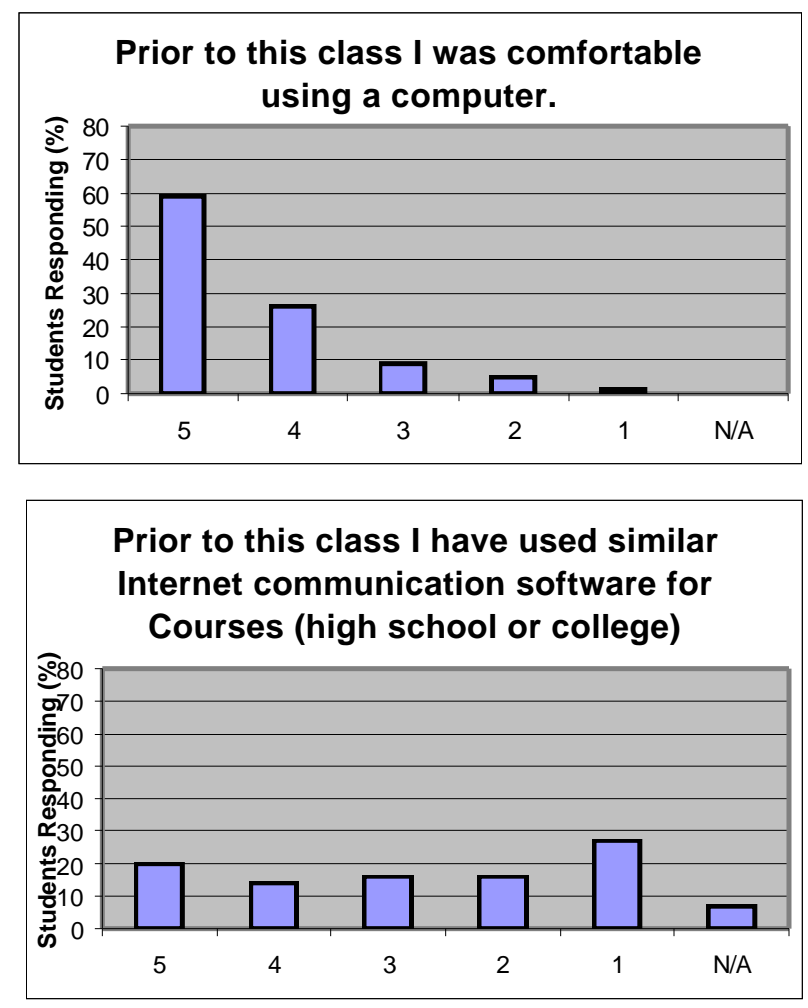


\section{Statements about the communication}
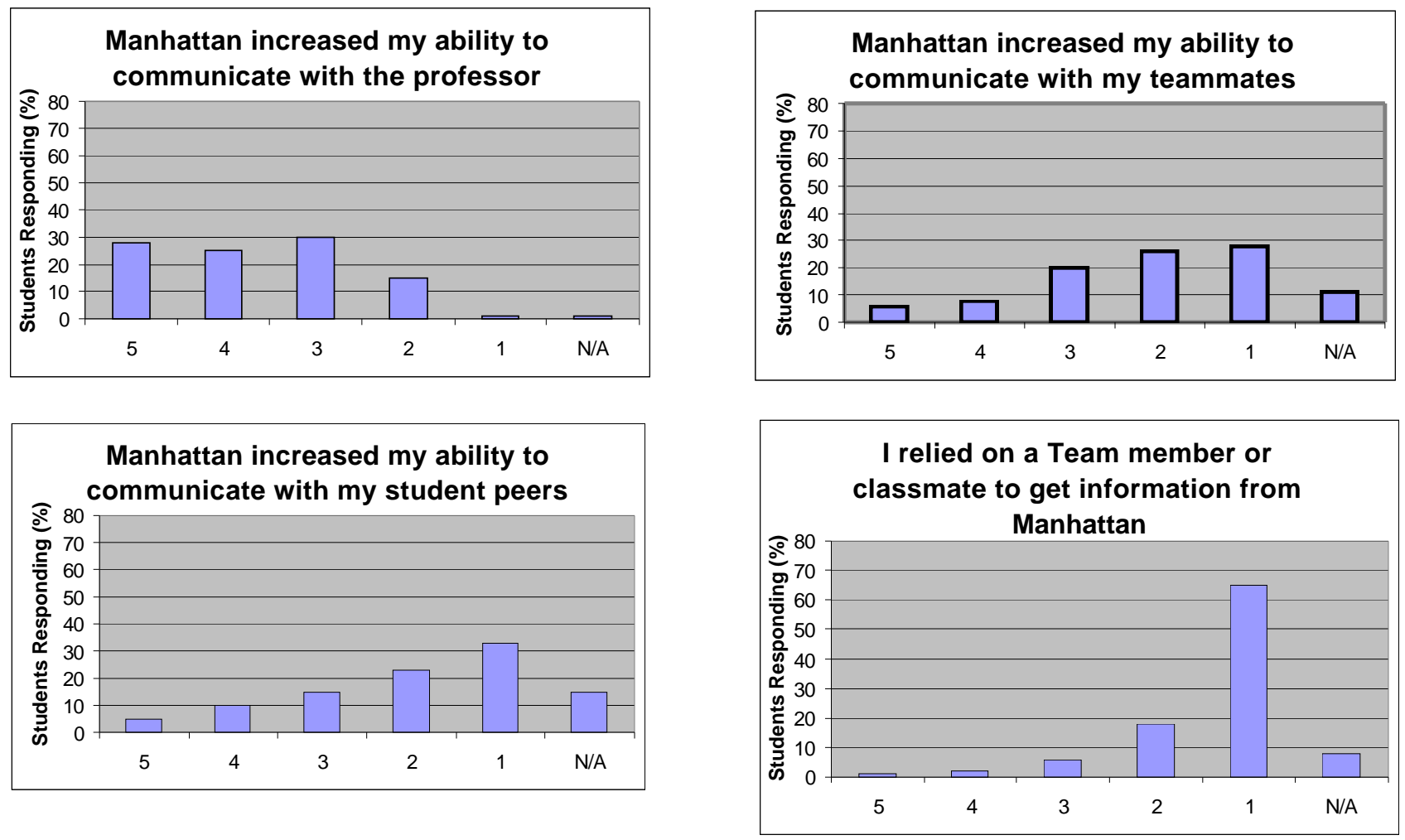

\section{Statements about learning}
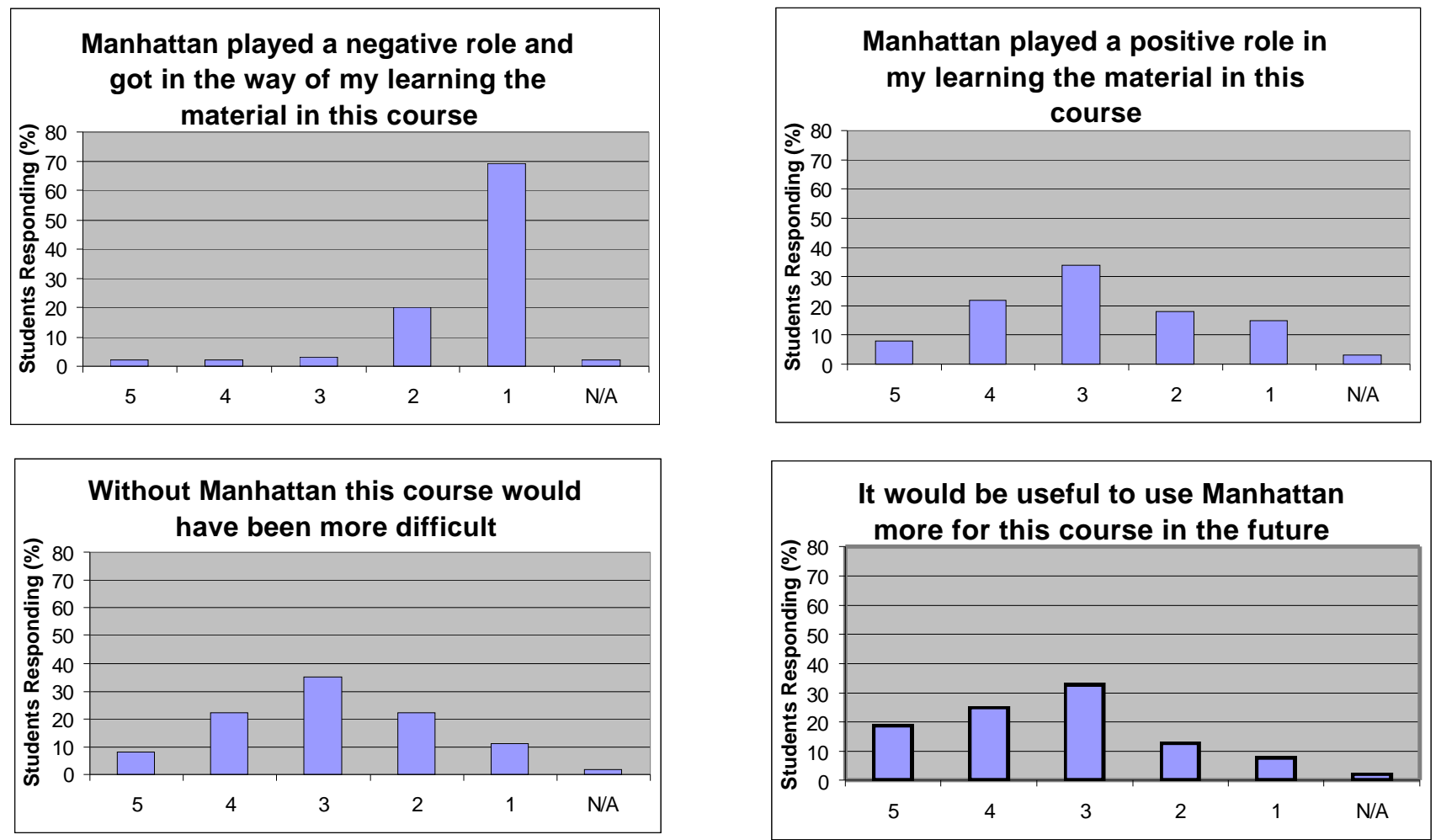

Proceedings of the 2002 American Society for Engineering Education Annual Conference \& Exposition Copyright $\odot$ 2002, American Society for Engineering Education 


\section{Statements about module usage}
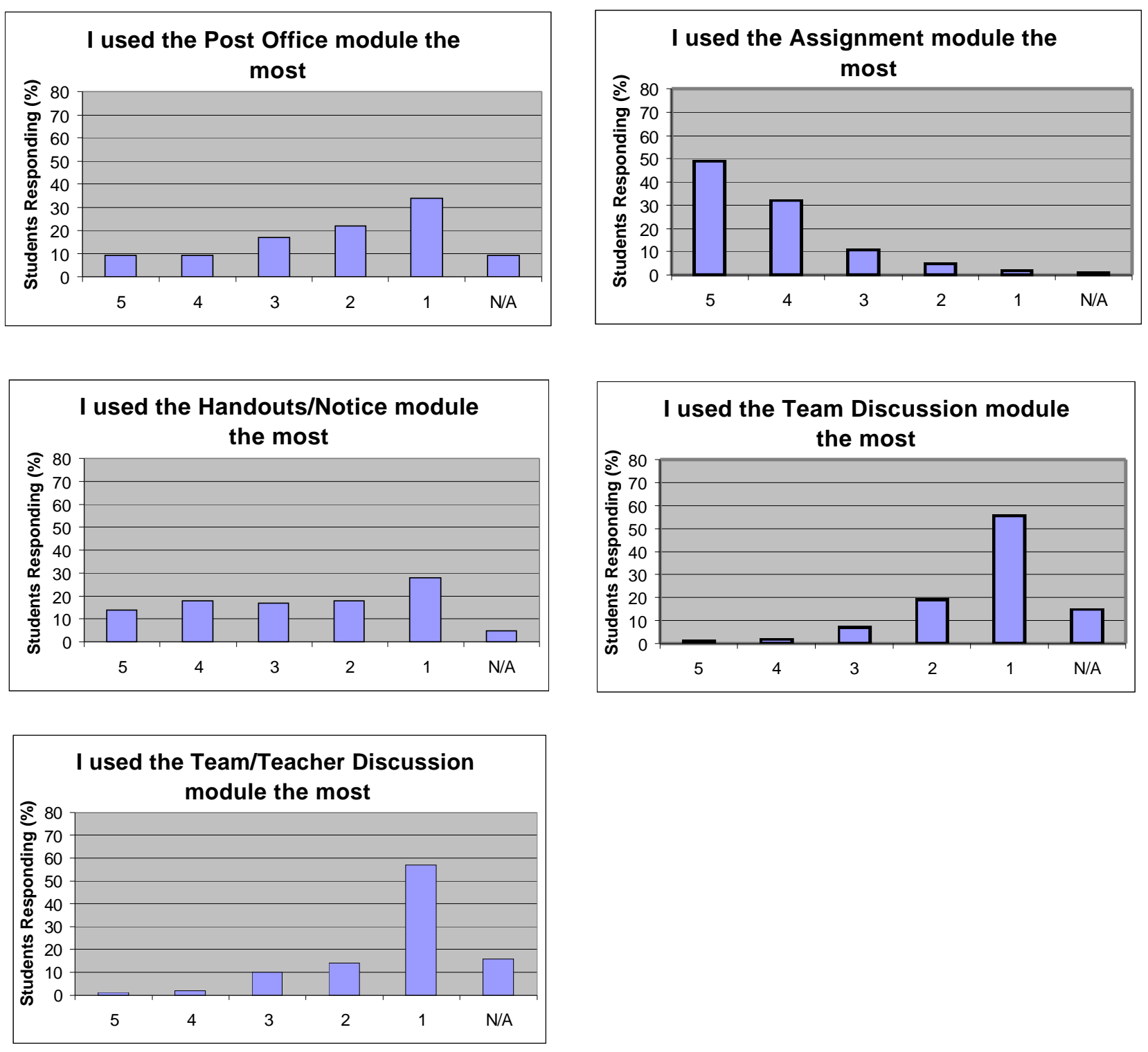


\section{STEVEN SCHREINER}

Steven Schreiner is an Assistant Professor and Coordinator of Biomedical Engineering Program at Western New England College in Springfield, Massachusetts. Dr. Schreiner received his Ph.D. and M.S.B.E at Vanderbilt University, and his B.S.E.E. at Western New England College. He held a two-year National Institutes of Health (NIH) postdoctoral fellowship at Johns Hopkins University. He has held engineering positions in industry and is a Registered Professional Engineer in Tennessee. His interests include engineering education, advanced surgical navigation devices, medical instrumentation, and medical imaging.

\section{THOMAS KEYSER}

Thomas K. Keyser is an Associate Professor of Industrial Engineering at Western New England College in Springfield, Massachusetts. Dr. Keyser received his Ph.D. in Industrial Engineering from Clemson University and his M.S. and B.S. degrees from the University of Southern Colorado and New Mexico State University respectively. Dr. Keyser has conducted research for the National Institute of Standards and Technology (NIST) and the National Science Foundation (NSF). His interests include engineering education, computer simulation, computer integrated manufacturing and applied operations research.

\section{RONALD E. MUSIAK}

Ronald E. Musiak is Professor of Electrical Engineering at Western New England College in Springfield, Massachusetts. Dr. Musiak received his Ph.D. at the University of Massachusetts, his M.S.E.E. at Virginia Polytechnic Institute, and his B.S.E.E. at Western New England College. He has held engineering positions in the electronics industry and continues to provide consulting to that industry.

\section{RICHARD MINDEK}

Richard B. Mindek, Jr. is an Assistant Professor of Mechanical Engineering at Western New England College in Springfield, Massachusetts. Dr. Mindek received his Ph.D., M.S. and B.S.M.E. at the University of Connecticut. He has held engineering positions in industry (in particular in jet engine design, performance analysis and manufacturing processes research). He held a postdoctoral fellowship at the National Institute of Standards and Technology (NIST) in Gaithersburg, MD where he continues to conduct manufacturing processes research.

\section{MARY B. VOLLARO}

Mary B. Vollaro is Assistant Professor of Engineering at Western New England College in Springfield, Massachusetts. Dr. Vollaro received her Ph.D. at the University of Connecticut, her M.S. at Rensselaer Polytechnic Institute, and her B.S.M.E. at Western New England College. She has held engineering positions in industry (in particular, the materials science area). 